\title{
Deleterious Influence of Hypothyroidism on Evolving Myocardial Infarction in Conscious Dogs
}

\author{
Ronald P. Karlsberg, David A. Friscia, Wilbert S. Aronow, and Sant S. Sekhon, \\ Cardiovascular Division, University of California Irvine and Veterans \\ Administration Medical Center, Long Beach, California 90822
}

\begin{abstract}
A B S TRACT To study the influence of hypometabolism on evolving myocardial infarction in a model with intact autoregulation, we investigated 53 awake dogs after coronary artery occlusion. Severe hypothyroidism was induced by the intravenous administration of ${ }^{131} \mathrm{I}$. Animals were instrumented to obtain hemodynamic measurements, and regional myocardial blood flow was measured with radioactive microspheres. Infarct size was determined by the creatine kinase depletion method, and dysrhythmia analysis was performed from 24 -h Holter monitor tapes in animals matched for infarct size. The microarchitecture of hypothyroid myocardium was determined by the electron microscope. Before coronary occlusion, mean systemic pressure in hypothyroid dogs was reduced by $14 \%$ and cardiac output reduced by $32 \%$, with no change in left ventricular end-diastolic pressure, first derivative of left ventricular pressure rise, $(\mathrm{dP} / \mathrm{dt})$, or heart rate. After coronary occlusion, there was deterioration in hemodynamic measurements in both groups, with lower absolute levels of mean systemic blood pressure and cardiac output obtained in hypothyroid dogs. Hypothyroidism was detrimental to evolving infarction with a $36 \%$ increase in infarct size present in hypothyroid dogs $(30 \pm 2 \%)$ compared to euthyroid controls $(22 \pm 3 \%), P<0.05$. Dysrhythmias were more severe in hypothyroid dogs. There were no changes in the relationship between regional myocardial blood flow and the extent of infarction after coronary occlusion. Abnormalities in microarchitecture were present in hypothyroid dog myocardium. Severe hypometabolism in this model was associated with alterations in hemodynamics, more severe dysrhythmias and changes in microarchitecture. The combined effect of
\end{abstract}

Presented in part at the 29th Annual Scientific Session, American College of Cardiology, Houston, Tex., 13 March 1980.

Address reprint requests to Dr. Karlsberg.

Received for publication 7 July 1980 and in revised form 6 November 1980. these alterations resulted in an overall detrimental influence of hypothyroidism on evolving myocardial necrosis in this model.

\section{INTRODUCTION}

In previous years, before the availability of many of the newer drugs for angina pectoris, the beneficial influence of hypothyroidism on ischemic myocardium was described in patients $(1-3)$. However, improvement of angina after induction of hypothyroidism may have been due to other factors such as reduced activity or placebo effects, since controlled studies were not performed, and other similarly dramatic treatments were found to have a strong placebo influence (4). Whether hypometabolism induced by hypothyroidism is actually beneficial to ischemic myocardium, and whether the intervention can limit the amount of evolving myocardial necrosis has never been established in an experimental model.

Hypothyroidism creates a hypometabolic situation that may be beneficial to ischemic myocardium by reducing myocardial energy requirements (5). This mechanism differs from the majority of interventions designed to be beneficial to ischemic myocardium, which have indirectly attempted to reduce energy demands by altering hemodynamic parameters such as left ventricular contractile state (6), afterload (7), or by improving coronary blood flow (8). On the other hand, hypothyroidism may result in a detrimental influence by impairing metabolic pathways (9), or by causing unfavorable hemodynamics (10). Some attempts designed to reduce infarct size have focused on altering the availability of metabolic substrate $(11,12)$. However, alteration of metabolic rate, such as possible with alteration in thyroid function, is difficult to accomplish clinically.

The study of hypometabolism on evolving infarction is important both from a theoretical and a practical viewpoint since future pharmacological approaches may attempt to directly reduce metabolic rate. We, therefore, investigated the effect of hypometabolism in- 
duced by reduced thyroid availability on evolving acute myocardial infarction in chronically instrumented awake, unsedated dogs. We studied the effects of hypothyroidism on: $(a)$ the hemodynamic response to acute coronary occlusion, $(b)$ the extent of myocardial damage as estimated from creatine kinase $(\mathrm{CK})^{1}$ depletion, $(c)$ the distribution of regional myocardial blood flow, $(d)$ the severity of postocclusion dysrhythmias, and $(e)$ the electron microarchitecture of myocardial tissue in our preparation.

\section{METHODS}

Animal preparations. Hypothyroidism was induced in 20 dogs by intravenous administration of $20 \mathrm{mCi}^{131} \mathrm{I}$. This method of producing hypothyroidism has advantages to thyroidectomy in the dog because this species has abundant extrathyroidal, thyroid tissue, the presence of which frequently results in incomplete surgical removal of thyroid tissue (13). $45 \mathrm{~d}$ after ${ }^{131} \mathrm{I}$ administration, thyroid function was determined using ${ }^{125} \mathrm{I}$ thyroxine radioimmunoassay (Corning Glass Works, Science Products Div., Corning, N. Y.). This test has been previously shown to be a reliable index of thyroid function in the dog (14). After induction of hypothyroidism documented by thyroid function and a significant weight gain, 17 of these animals and 30 euthyroid controls underwent surgical instrumentation. Three euthyroid controls and three hypothyroid animals were not instrumented and were used for electron microscopic studies.

Dogs were anesthetized with $15 \mathrm{mg} / \mathrm{kg}$ thiopental, intubated, and given halothane $(0.05 \%)$ and oxygen $(100 \%)$. A left thoractomy was performed; the heart was suspended in a pericardial cradle. In 16 euthyroid controls (control group $\mathbf{A}$ ) and 17 hypothyroid dogs, the left anterior descending coronary artery was dissected free beyond the first medial branch, 20 $\mathrm{mm}$ from the origin of the artery. A 00 -silk suture was placed loosely around the vessel and both ends of the suture exteriorized and secured to the skin through a polyethylene tube (PE 240). In 14 euthyroid dogs, larger infarctions were produced by higher occlusion (control group B). A Konigsberg (P-22) catheter tipped manometer (Konigsberg Instruments, Inc., Pasadena, Calif.) was placed in the left ventricular cavity through an apical stab wound. A needle was also placed temporarily in the left ventricle for pressure determinations, thus allowing the calibration of the manometer. An electromagnetic flow transducer (Micron Instruments, Inc., Los Angeles, Calif.) was placed around the ascending aorta in an area free of connective tissue and externalized. Catheters were placed in the carotid artery and exteriorized. Exteriorized coronary snares and left atrial catheters were placed in four hypothyroid and four euthyroid dogs (from control group A) for the determination of regional myocardial blood flow.

After the animals recovered from surgery (4-7 d), they were trained to lie quietly on a table without restraints. Manipulations were performed in a uniform method by the same experimenters. The animals were cared for according to the guidelines outlined by the Institute of Laboratory Animal Resources, National Research Council (National Institutes of Health, publication No. 78-23), and the guiding principles of the American Physiological Society. Hemodynamics were recorded on an Electronics for Medicine (Pleasantville, N. Y.) recorder. The carotid pressures were measured with Statham

${ }^{1}$ Abbreviations used in this paper: CK, creatine kinase; LVEDP, left ventricular end-diastolic pressure.
P-23 Db transducers (Statham Instruments Inc., Oxnard, Calif.). The left ventricular systolic and left ventricular enddiastolic pressures were recorded in millimeters of mercury per second from the micromanometer tipped catheter. The maximum rate of rise of the left ventricular pressure $(d P / d t)$ was obtained from differentiation of the left ventricular pressure by an Electronics for Medicine RC differentator. The use of catheter tipped microtransducers avoids artifact present when fluid filled systems are used to measure $d P / d t$. An electrocardiographic Holter monitor recorder (Electro-Cardiocoder, Del Mar Avionics, Irvine, Calif.) was placed on all animals and removed $24 \mathrm{~h}$ after coronary occlusion. After stable hemodynamics were obtained, hemodynamics were recorded for $1 \mathrm{~h}$ before coronary occlusion. Myocardial infarction was produced by tightening the snare around the coronary artery. Hemodynamics were recorded every $5 \mathrm{~min}$ for $1 \mathrm{~h}$ after occlusion. In dogs that had measurement of regional myocardial blood flow, ${ }^{141}$ Cerium or ${ }^{85}$ Strontium (Minnesota Mining \& Manufacturing Co., St. Paul, Minn.) were injected into the left atrium before and $1 \mathrm{~h}$ after coronary occlusion. The order of the injections was randomly varied. A reference flow from the arterial catheter was started a few seconds before and collected for $3 \mathrm{~min}(15,16)$. At the end of $24 \mathrm{~h}$ the animals were killed with an overdose of thiopental and complete coronary occlusion verified.

Estimates of infarct size. Estimates of infarct size were obtained from the determination of CK depletion $(17,18)$. After the animals were killed, the hearts were rapidly excised and blood drained from the chambers. The left ventricle and septum were removed and washed for $1 \mathrm{~min}$ in saline at $4^{\circ} \mathrm{C}$, blotted dry, weighed, and stored at $30^{\circ} \mathrm{C}$. At the time of analysis (within $1 \mathrm{mo}$ ), hearts were allowed to thaw slowly. Four transmural samples from nonischemic regions of the posterior left ventricular free wall were homogenated and diluted $(10 \mathrm{ml} / \mathrm{g})$ in media consisting of saline, $0.005 \mathrm{M}$ EGTA, and $0.001 \mathrm{M} 2$-mercaptoethanol, and centrifuged at $15,000 \mathrm{~g}$ for $20 \mathrm{~min}$ at $4^{\circ} \mathrm{C}$. The remainder of the left ventricle was minced and homogenized in the same medium and also centrifuged. The supernate was analyzed for CK content by the Oliver-Rosalki assay and results expressed at international units per gram of tissue as described $(17,18)$. Samples were assayed with and without creatine phosphate, the specific substrate for CK, to exclude activity from other than CK.

Estimates of infarct size were based on analysis of myocardial CK depletion normalized for left ventricular weight. Myocardial CK depletion was determined by subtracting the measured CK activity in the infarcted ventricle (including CK content of biopsies) from the expected CK activity obtained by multiplying total ventricular weight by the average CK activity per gram of normal myocardium. The ratio of depleted myocardial CK to that expected was expressed as the percentage of myocardial CK depleted $(17,18)$. This method of determining myocardial infarct size is independent of plasma CK activity, and results correlate with estimates of infarct size based on morphometric (19), physiologic (18), and radioisotopic techniques (20). This approach for estimating infarct size may better account for areas of heterogenous infarction in which histological or morphometric criteria of infarction may be difficult to apply (5). This method produces relatively uniform infarct sizes with small standard errors, which allow comparisons between groups of animals with modest numbers of experiments $(21)$. We have previously shown that thyroxine per se does not affect the CK assay (22). In addition, there are no known circulating inhibitory or facilitating substances in hypothyroid canine plasma or myocardium (22).

Dysrhythmia analysis. Since the extent of necrosis is related to the severity of dysrhythmias (23), select dogs from control group A (excluding dogs with left atrial catheters) and con- 
trol group B were matched for infarct size with the hypothyroid dogs for analysis of dysrhythmias. Holter monitor tapes were analyzed by scanning the tapes and determining the percentage of abnormal beats for each half-hour period.

Myocardial blood flow determination. In the four hypothyroid dogs and four euthyroid dogs in which myocardial blood flow was determined, an average of 10, 1-2 $\mathrm{g}$ biopsies from all areas of the left ventricle were minced and packed into glass vials (up to standard height) and counted in a well counter. There was no appreciable overlap between counting spectrums chosen for ${ }^{141}$ Cerium and ${ }^{85}$ Strontium in standard solutions. The reference sample was also counted and regional myocardial blood flow determined by formulae previously described $(15,16)$. In the same biopsies, the extent of infarction was determined by the CK depletion method.

For electron microscopic analysis, biopsies were obtained from three hypothyroid dogs and an additional three euthyroid dogs who had not undergone instrumentation. In these dogs the proximal left anterior descending coronary artery was isolated and cannulated with a 16-gauge catheter, and the heart rapidly perfused with $2.5 \%$ phosphate-buffered glutaraldehyde under $200 \mathrm{~mm} \mathrm{Hg}$ for $5 \mathrm{~min}$. Perfusion fixation improves the preservation of biological ultrastructure (24). Before the onset of perfusion with fixative, no interruption of blood flow was allowed. Biopsies from the fixed tissue were obtained with a punch drill, and were immediately placed in a $2.5 \%$ phosphate-buffered glutaraldehyde for an additional 2 h. After a 3-h rinse with six changes of fresh phosphate buffer, the tissue was post-fixed for $2 \mathrm{~h}$ in cold $1 \%$ phosphate-buffered osmium tetroxide. Dehydration was accomplished in a graded series of alcohol. After infiltration with propylene oxide, the tissue was placed in a mixture of $1 / 2$ propylene oxide and $1 / 2$ araldite at room temperature overnight. The tissue was then embedded in pure araldite in preformed capsules. The blocks of tissue were allowed to cure in the oven at $60^{\circ} \mathrm{C}$ overnight. The sections were stained with uranyl acetate and lead citrate, and examined with an RCA EMU-3E electron microscope (RCA Electro-Optics \& Devices, RCA Solid State Div., Lancaster, $\mathrm{Pa}$.).

Statistics. Three hypothyroid dogs and six controls (two group A, four group B) were eliminated from all data analysis because they died after coronary occlusion and before complete data was obtained. This left 10 animals in the experimental hypothyroid group, 10 animals in control group $A$, and 10 animals in control group B, for analysis of infarct size, hemodynamics, and dysrhythmias.

Mean $\pm S E M$, paired and nonpaired $t$ test, correlation coefficients, linear regression equations, and Fisher's exact probability test were calculated on a Texas Instruments programmable 59 computer with a PC100A printer (Texas Instruments Inc., Digital Systems Div., Houston, Tex.).

\section{RESULTS}

Hypothyroidism and infarct size. Intravenous treatment with ${ }^{131} \mathrm{I}$ resulted in a $68 \%$ reduction in thyroid function as measured by the thyroxine radioimmunoassay. Control values were $2.02 \pm 1 \mu \mathrm{g} / \mathrm{dl}$ compared to $0.65 \pm 1 \mu \mathrm{g} / \mathrm{dl} 45 \mathrm{~d}$ after ${ }^{131} \mathrm{I}(P<0.01)$. Hypothyroid animals were lethargic and had a weight increase from $17.8 \pm 0.9$ to $19.8 \pm 0.9 \mathrm{~kg},(P<0.01)$ with no change in weight of euthyroid dogs over the same period of time. Despite the increase in total body weight, the left ventricle weight of dogs with hypothyroidism $(74 \pm 6 \mathrm{~g})$ was no different from left ventricular weight of euthyroid dogs $(83 \pm 7 \mathrm{~g})$.
The extent of myocardial damage as estimated from CK depletion was $36 \%$ greater in the 10 hypothyroid dogs $(30 \pm 2 \%)$ than in the 10 euthyroid dogs of control group A $(22 \pm 3 \%), P<0.05$. There was no evidence that hypothyroidism, per se, affected the activity of myocardial CK since CK activity in noninfarcted hypothyroid myocardium $(1,963 \pm 63 \mathrm{IU} / \mathrm{g})$ was similar to $\mathrm{CK}$ activity in noninfarcted euthyroid myocardium $(1,874 \pm 73$ $\mathrm{IU} / \mathrm{g})$.

Hemodynamics. The hemodynamics of the hypothyroid dogs during the $1 \mathrm{~h}$ before coronary occlusion were compared to the hemodynamics of the euthyroid dogs (control group A). Heart rate in hypothyroid dogs (116 \pm 6 beats $/ \mathrm{min}$ ) was similar to heart rates in euthyroid dogs $(120 \pm 7$ beats/min). Mean systemic pressure was reduced in hypothyroid dogs $(81 \pm 2.4 \mathrm{~mm} \mathrm{Hg})$ in comparison to euthyroid dogs $(94 \pm 4 \mathrm{~mm} \mathrm{Hg}), P<0.01$. Cardiac output was also reduced in hypothyroid dogs $(1,460 \pm 70$ liters $/ \mathrm{min})$ compared to euthyroid controls $(2,150 \pm 60$ liters $/ \mathrm{min}), P<0.01$. This reduction in cardiac output was associated with no change in left ventricular end-diastolic pressure (LVEDP), which was similar in euthyroid and hypothyroid dogs $(5 \pm 1$, $5 \pm 2 \mathrm{~mm} \mathrm{Hg}$, respectively).

The first derivative of left ventricular pressure rise $d P / d t$ in hypothyroid dogs $(2,066 \pm 45 \mathrm{~mm} \mathrm{Hg} / \mathrm{s})$ was not different than in euthyroid dogs $(1,927 \pm 81 \mathrm{~mm} \mathrm{Hg} / \mathrm{s})$. An expected reduction in $d P / d t$ in hypothyroid dogs may have been obliterated by reflex increase in $d P / d t$ due to the reduction in the blood pressure (25). After coronary occlusion, hemodynamics deteriorated in both euthyroid controls and hypothyroid dogs. Figs. 1-4 show changes in blood pressure, cardiac output, LVEDP, and $d P / d t$. Blood pressure (Fig. 1) and cardiac output (Fig. 2) were reduced by a similar magnitude from preocclusion levels in both groups. However, since preocclusion values were lower in hypothyroid dogs, absolute values after coronary occlusion were lower in hypothyroid dogs $(P<0.01)$. The lowest mean blood pressure in hypothyroid dogs was $63 \pm 6 \mathrm{~mm} \mathrm{Hg}$ at $10 \mathrm{~min}$ after occlusion, and this level was sustained for $10 \mathrm{~min}$ (Fig. 1). LVEDP after occlusion was increased similarly in both groups (Fig. 3). $d P / d t$ was reduced after coronary occlusion similarly in both groups (Fig. 4).

Dysrhythmias. 10 euthyroid dogs from control group A and B with matched infarct size to the hypothyroid group were chosen for dysrhythmia analysis. Infarct size in this group averaged $31 \pm 2 \%$ compared to $30 \pm 2 \%$ in hypothyroid dogs. Heart rate in the $1 \mathrm{~h}$ before occlusion and over the following $24 \mathrm{~h}$ after occlusion was similar in both groups with a progressive tachycardia peaking at $\sim 12 \mathrm{~h}$ (Fig. 5). Both groups had the onset of multifocal ventricular tachycardia at the same time after coronary occlusion. $40 \%$ of all beats were multifocal ventricular tachycardia at $5.9 \pm 0.9 \mathrm{~h}$ 


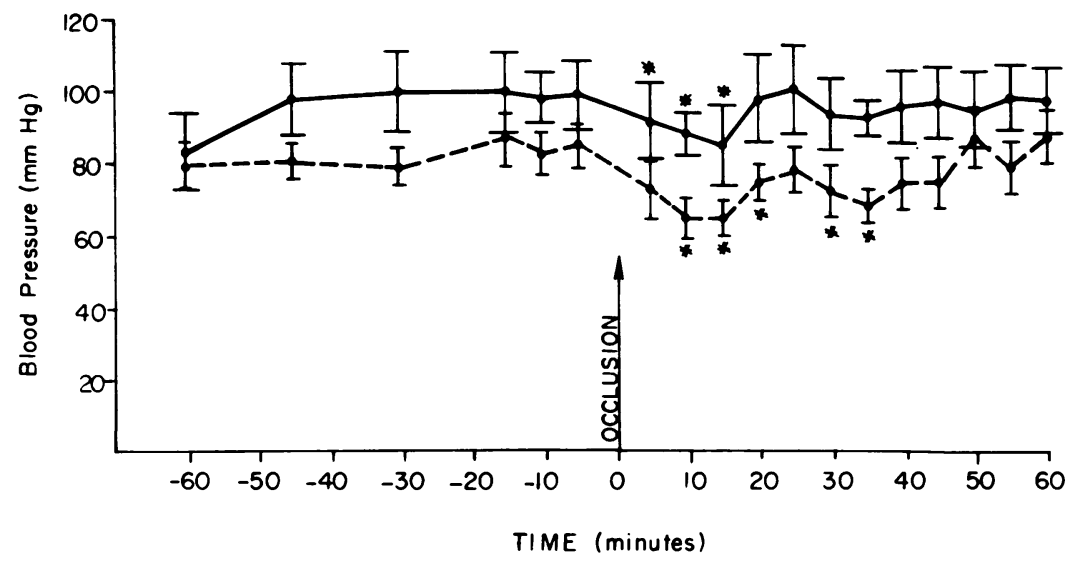

FIGURE 1 Mean systemic blood pressure $1 \mathrm{~h}$ before and after coronary occlusion in euthyroid control ( $(-)$ and hypothyroid (-----) dogs. Bars represent standard error of the mean. Asterisk indicates $P<0.05$ comparing values after coronary occlusion to values before coronary occlusion in each group. During the control period, mean systolic blood pressure was lower in hypothyroid dogs (Results). Deterioration occurred in both groups after occlusion with lower absolute blood pressure present in hypothyroid dogs.

after occlusion in euthyroid dogs, and $5.3 \pm 0.3 \mathrm{~h}$ in hypothyroid dogs. Despite the similar postocclusion heart rates, hypothyroid dogs had a consistently greater percentage of abnormal beats with a wide variation in both groups (Fig. 6). After multifocal ventricular tachycardia was established, abnormal beats were more frequent in hypothyroid dogs comprising $82 \pm 5 \%$ of all complexes compared to $50 \pm 5 \%$ of complexes in controls ( $P$ $<0.01)$. In addition, periods of second or third degree atrioventricular block occurred in four hypothyroid dogs, but not in control dogs $(P<0.05)$.

Regional myocardial blood flow. The reduced car- diac output, mean systemic blood pressure, and greater ventricular dysrhythmias in hypothyroid dogs could potentially result in alteration of regional myocardial blood flow, and thereby explain the detrimental effects observed. Accordingly, we evaluated regional coronary blood flow in four hypothyroid and four euthyroid dogs with radioactive microspheres. Before coronary occlusion, average regional myocardial blood flow was lower in hypothyroid dogs $(106 \pm 39 \mathrm{ml} / \mathrm{min}$ per $100 \mathrm{~g})$ than in euthyroid dogs $(188 \pm 29 \mathrm{ml} / \mathrm{min}$ per $100 \mathrm{~g}), P$ $<0.01$. This difference may have been due to the reduced systemic pressure and cardiac output in these

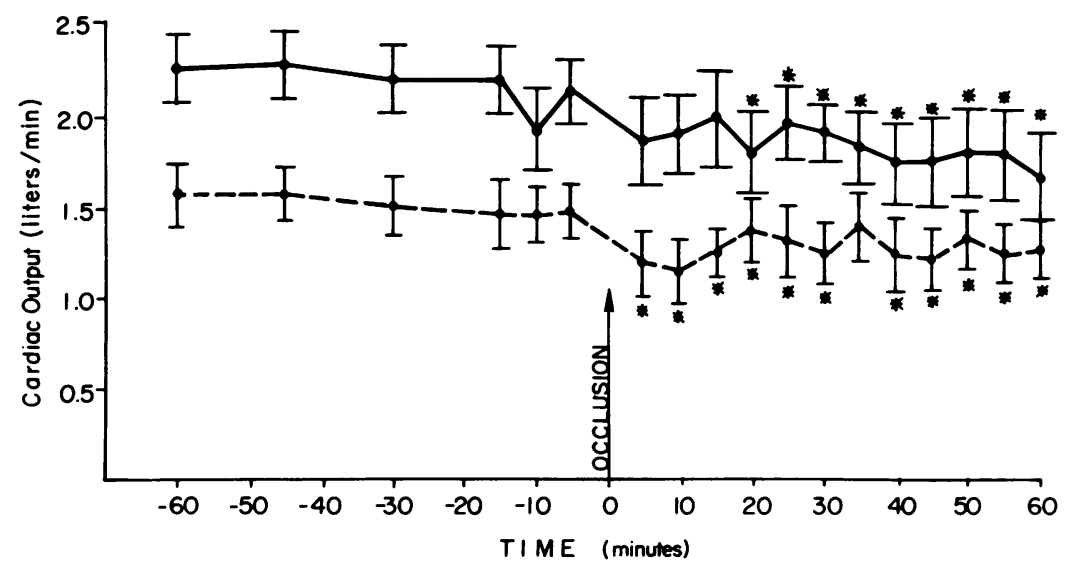

FIGURE 2 Cardiac output $1 \mathrm{~h}$ before and after coronary occlusion in euthyroid control (-) and hypothyroid (----) dogs. Bars represent standard error of the mean. Asterisk indicates $P$ value $<0.05$ comparing values after coronary occlusion to values before coronary occlusion in each group. During the control period, cardiac output was lower in hypothyroid dogs (Results). Deterioration occurred in both groups after occlusion with lower absolute cardiac output present in hypothyroid dogs. 


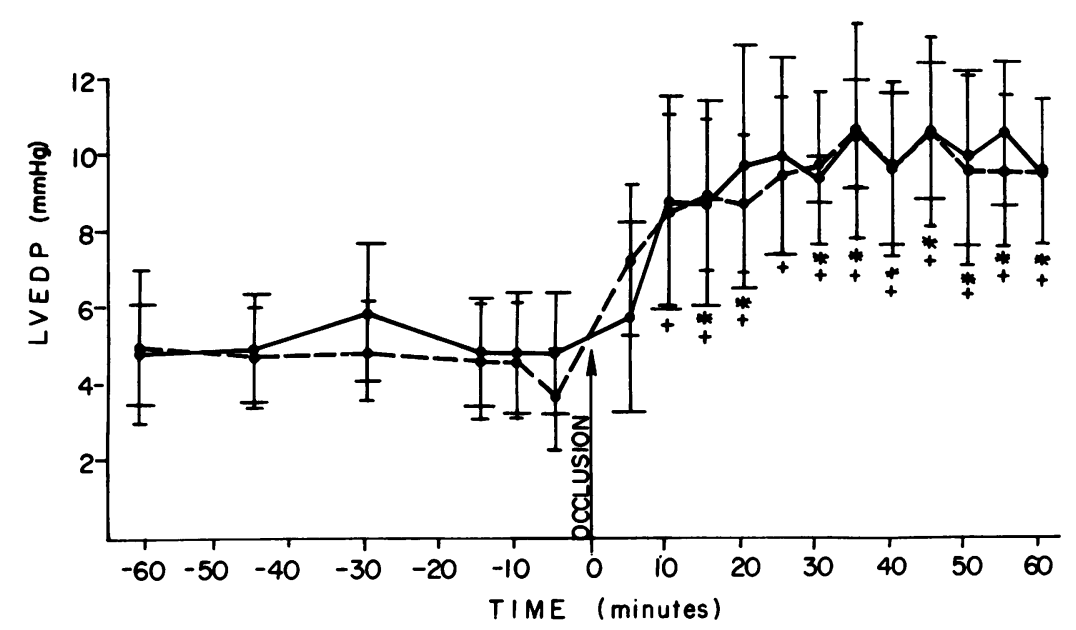

FIGURE 3 LVEDP $1 \mathrm{~h}$ before and after coronary occlusion in euthyroid control (-) and hypothyroid (----) dogs. Bars represent standard error of the mean. Asterisk (euthyroid) or plus (hypothyroid) indicates $P$ value $<0.05$ comparing values after occlusion to values prior to occlusion in each group. There were no significant differences between groups at any time. LVEDP increased after occlusion in both groups.

animals, and possibly the reduced myocardial oxygen consumption reported by others in hypothyroid hearts (26).

$1 \mathrm{~h}$ after coronary occlusion, blood flow in both groups was reduced in areas that became infarcted, but not in areas which remained normal (Fig. 7). The severity of infarction as defined by CK depletion at $24 \mathrm{~h}$ after occlusion correlated to the magnitude of blood flow reduction $1 \mathrm{~h}$ after occlusion in a similar manner in both hypothyroid and euthyroid dogs. Correlation coefficients between regional myocardial blood flow and CK depletion varied between 0.91 and 0.98 in individual experiments and were not different between groups (Table I). There was no significant difference in the slope or the $y$ intercept of these regression equations indicating a relative uniform relationship between blood flow and CK depletion in the control and hypothyroid animals, Blood flow in normal areas (CK

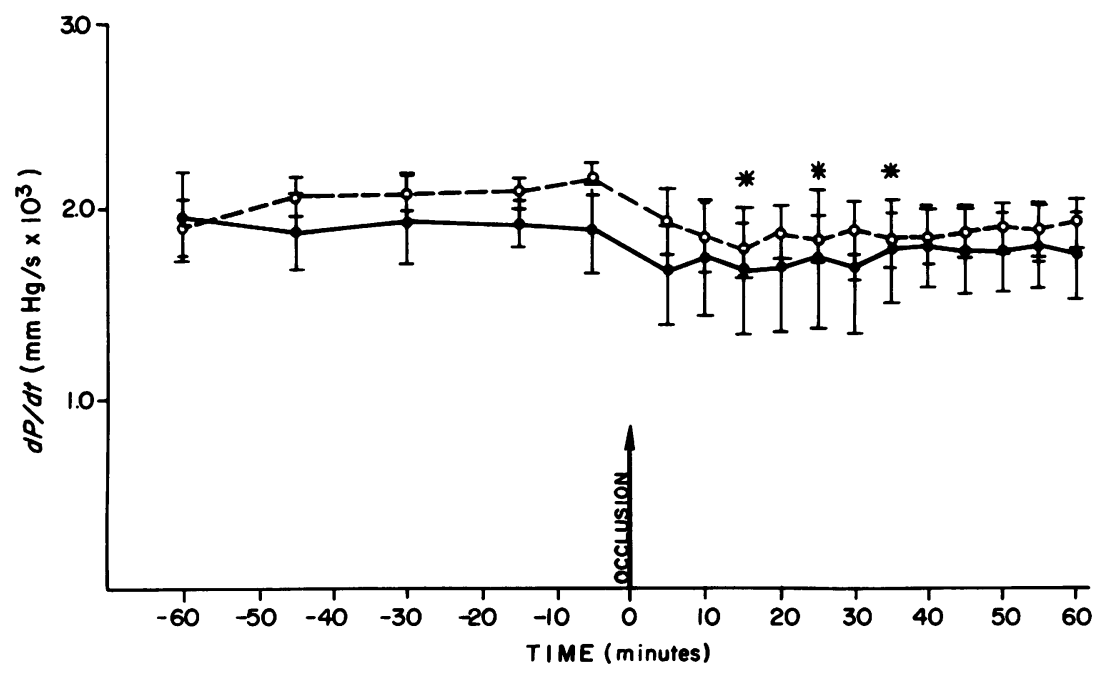

FIGURE 4 The first derivation of left ventricular pressure rise (dP/dt) $1 \mathrm{~h}$ before and after coronary occlusion in euthyroid control $(-)$ and hypothyrioid (----) dogs. Bars represent SEM. Asterisk indicates $\boldsymbol{P}$ value $<0.05$ comparing values after coronary occlusion in values before coronary occlusion in each group. There were no significant differences between groups at any time. After coronary occlusion, deterioration of $d P / d t$ reached significance in hypothyroid dogs, and there was a trend toward lower $d P / d t$ in euthyroid controls. 


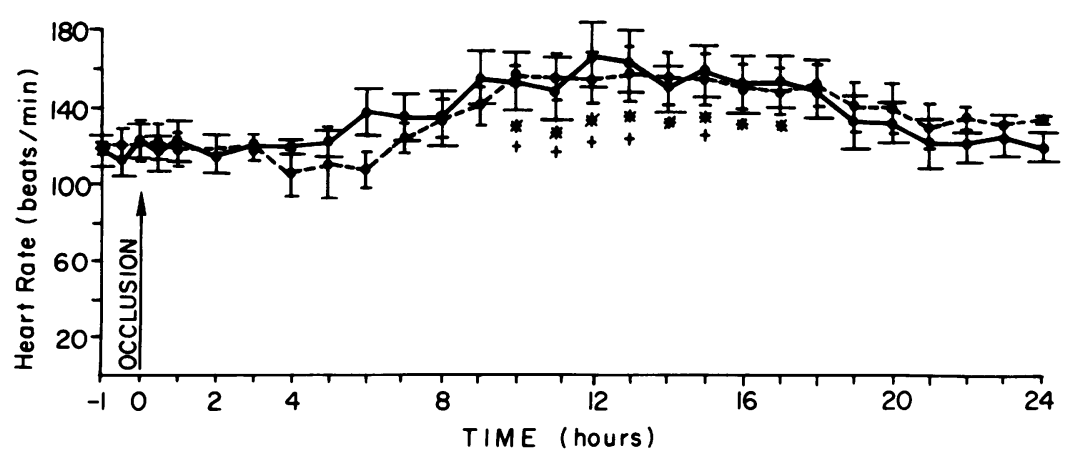

Figure 5 Heart rate in euthyroid controls (-) and hypothyroid (-----) dogs $1 \mathrm{~h}$ before occlusion and for $24 \mathrm{~h}$ after occlusion. Infarct size of euthyroid controls was matched to infarct size of hypothyroid dogs (see text). Bars represent SEM. There were no differences in heart rate between euthyroid and hypothyroid dogs. After occlusion tachycardia was present in both groups. Symbols $\left({ }^{*}\right.$ and + ) indicate $P<0.05$ and 0.5 , respectively.

$>1,500 \mathrm{IU} / \mathrm{g})$, moderately infarcted areas (CK 1,500 IU/ $\mathrm{g}$ to $1,000 \mathrm{IU} / \mathrm{g}$ ), and severely infarcted areas (CK $<1,000 \mathrm{IU} / \mathrm{g}$ ) were similarly reduced in both euthyroid and hypothyroid dogs (Fig. 7). Since the relationship between regional blood flow and regional infarction remained unaltered by hypothyroidism, it was unlikely that the detrimental influence of hypothyroidism could be explained on the basis of regional alterations in coronary perfusion after ligation.

Electron microscopy. Myocardium from controls and hypothyroid dogs which had not undergone instrumentation were examined with the electron microscope. Myocardium of control specimens appeared to have normal cytoarchitecture (Fig. 8). However, mitochondria in hypothyroid tissue appeared to be fewer in number. Some areas of tissue in hypothyroid hearts were devoid of mitochondria (Fig. 9). This reduction of density of mitochondria was associated with marked elongated mitochondria that often occupied multiple sacromeres (Fig. 10). Such unusually elongated, rodshaped bodies in some views appeared to be formed by coalescence of one or more mitochondria and were not seen in euthyroid myocardium.

\section{DISCUSSION}

In this experimental preparation, reduction of thyroid availability resulted in a hypothyroid state that was detrimental to ischemic myocardium, and resulted in extension of myocardial infarction. Evidence for the detrimental influence on evolving myocardial infarction by hypothyroidism was greater infarct size as determined by depletion of the intracellular enzyme CK, the reduction in preocclusion hemodynamics with greater absolute deterioration after coronary occlusion, and greater ventricular dysrhythmias compared to eu-

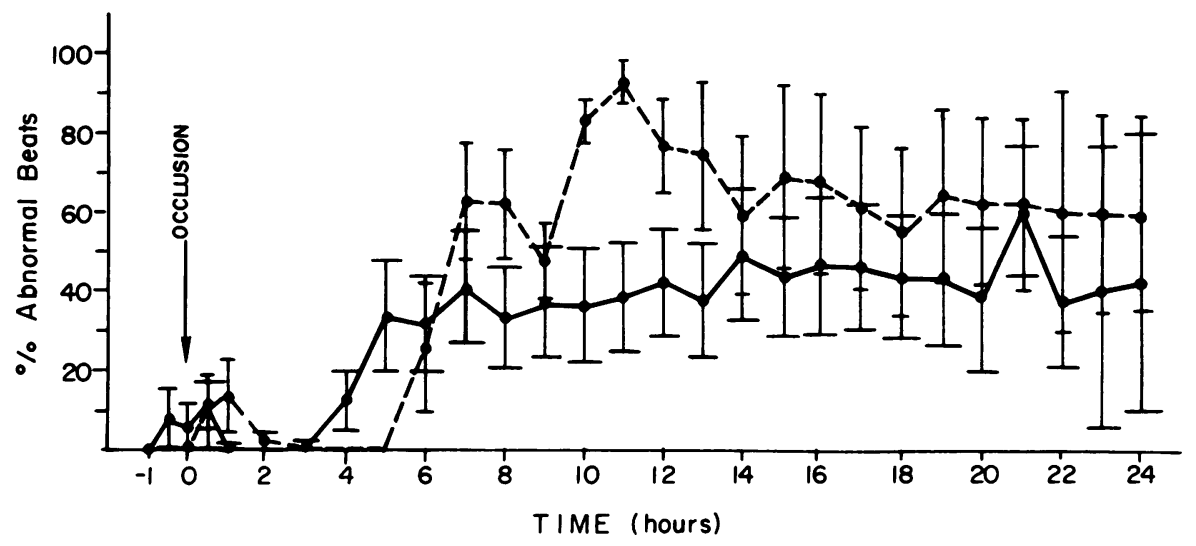

FIGURE 6 Percentage of abnormal beats in euthyroid controls (-) and hypothyroid (----) dogs $1 \mathrm{~h}$ before occlusion and twenty-four hours after occlusion. Infarct size of euthyroid dogs was matched to infarct size of hypothyroid dogs. Bars represent SEM. There was a greater number of abnormal beats in hypothyroid dogs than euthyroid controls after occlusion (Results). 


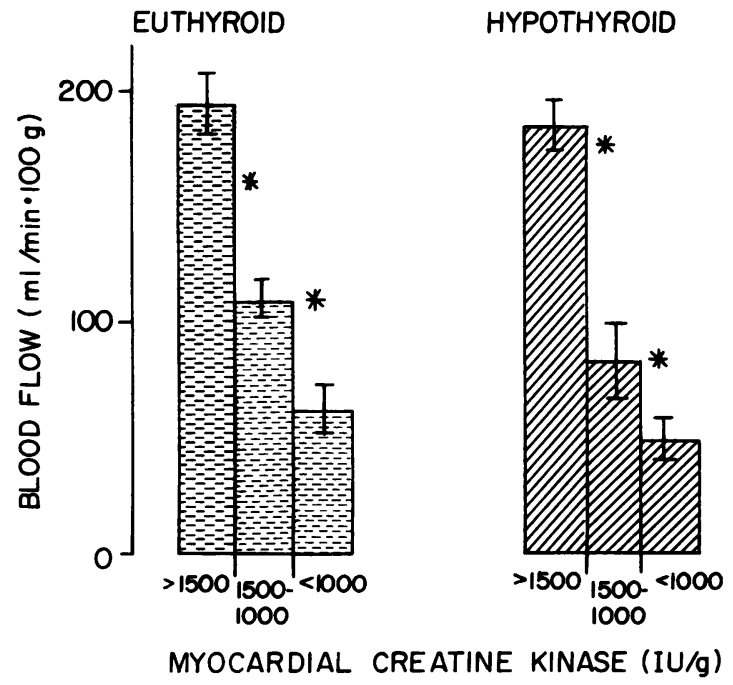

FIGURE 7 Regional myocardial blood flow in euthyroid controls (left) and hypothyroid dogs (right). Blood flow ( $\mathrm{ml} / \mathrm{min}$ per $100 \mathrm{~g}$ ) was determined in biopsies by the radioactive microsphere technique. In the same biopsies the extent of myocardial damage was established by analysis of CK. Normal areas (CK $>1,500 \mathrm{IU} / \mathrm{g})$ had greater blood flow than border areas (CK 1,500-1,000 IU/g) or infarcted areas (CK $<1,000 \mathrm{IU} / \mathrm{g}$ ) in both groups. Asterisk indicates $P<0.01$. Bars represent SEM. There were no significant differences between normal, border, or infarcted areas when hypothyroid dogs were compared to euthyroid controls.

thyroid controls. These detrimental influences did not change the relationship of regional myocardial blood flow after coronary occlusion to the extent of infarction.

We did not measure changes in global left ventricular blood flow and it is possible that reduction in coronary blood flow had a role in extending the amount of infarction in hypothyroid dogs. The evidence to suggest a reduction of global left ventricular blood flow after coronary occlusion in this hypothyroid preparation include: $(a)$ an unaltered relationship between the extent of infarction, and postocclusion reduction of blood flow in hypothyroid and euthyroid dogs with a greater overall infarct size in hypothyroid dogs, $(b)$ reduction in regional myocardial blood flow in hypothyroid dogs compared to euthyroid controls prior to coronary occlusion, $(c)$ a reduction in driving coronary perfusion pressure (27) by greater reduction in mean systemic pressure and cardiac output after occlusion in hypothyroid dogs, and $(d)$ as reported by others, a reduction in myocardial oxygen consumption in the hypothyroid state (26), which is known to greatly reduce myocardial blood flow (28). All of these factors would tend to reduce global coronary blood flow to a greater extent in hypothyroid dogs after coronary occlusion. However, changes in coronary blood flow over the range of changes in perfusion pressure observed in this experiment can be expected to be modest (29)
TABLE I

Relationship between Regional Myocardial Blood Flow 1 h after Coronary Occlusion and the Extent of Infarction (CK Depletion) Determined $24 \mathrm{~h}$ after Occlusion

\begin{tabular}{lcrcc}
\hline & Dog No. & \multicolumn{1}{c}{$b$} & $m$ & $r$ \\
\hline Control & 1 & 0.15 & 0.71 & 0.95 \\
& 2 & -0.12 & 1.27 & 0.97 \\
& 3 & 0.28 & 0.80 & 0.98 \\
Mean & 4 & 0.04 & $\underline{0.75}$ & $\underline{0.98}$ \\
SD & & 0.09 & 0.88 & 0.97 \\
Hypothyroid & 1 & 0.17 & 0.26 & 0.01 \\
& 2 & -0.15 & 0.72 & 0.91 \\
& 3 & -0.57 & 1.01 & 0.97 \\
Mean & 4 & 0.15 & $\underline{0.90}$ & 0.95 \\
SD & & -0.21 & 0.99 & 0.95 \\
& & 0.30 & 0.25 & 0.03 \\
\hline
\end{tabular}

Results of calculation of regression equations: ${ }^{*} y=m x+b$, where $y=$ blood flow $(\mathrm{ml} / \mathrm{min} \cdot \mathrm{g}) ; x$, myocardial CK activity $(\mathrm{IU} / \mathrm{g}) ;$ slope $(\mathrm{ml} / \mathrm{min} \cdot \mathrm{g} / \mathrm{IU} / \mathrm{g}) ; b, y$ intercept $(\mathrm{ml} / \mathrm{min} \cdot \mathrm{g})$; $r=$ correlation coefficient.

and may not be detrimental if in response to reduced myocardial oxygen consumption.

The findings of a detrimental influence of hypothyroidism on evolving infarction are not consistent with the expected findings of a beneficial effect based on the hypothesis that hypometabolism caused by reduced thyroid availability would favorably alter the balance between myocardial oxygen consumption and demand by reducing metabolic rate (30). In part, this may be explainable, since metabolic rate appears to be a minor determinant of oxygen use compared to the energy requirements due to intramyocardial tension, contractile state, and heart rate $(31,32)$. It is well established that thyroid hormone has direct and indirect intracellular actions that regulate the rate of metabolism $(33,34)$. The alteration of the rate of oxygen consumption may be, in part, independent of the indirect alterations in hemodynamics induced by thyroxine, but nevertheless, these indirect effects may influence oxygen consumption greatly (35).

It is possible that the severe reduction in thyroid availability caused an unfavorable effect on metabolism by impairing metabolic reactions such as oxidative phosphorylation (9), or protein synthesis (36). Other factors altered may include myocardial catecholamine sensitivity (37), turnover (38), or alteration of binding sites $(39,40)$, availability of adenyl cyclase $(41,42)$, functioning of the sodium (43), or calcium pump (44), effects on myosin adenosine (45), or a variety of other metabolic effects $(46,47)$. These metabolic effects may also be related to the morphological abnormalities ob- 


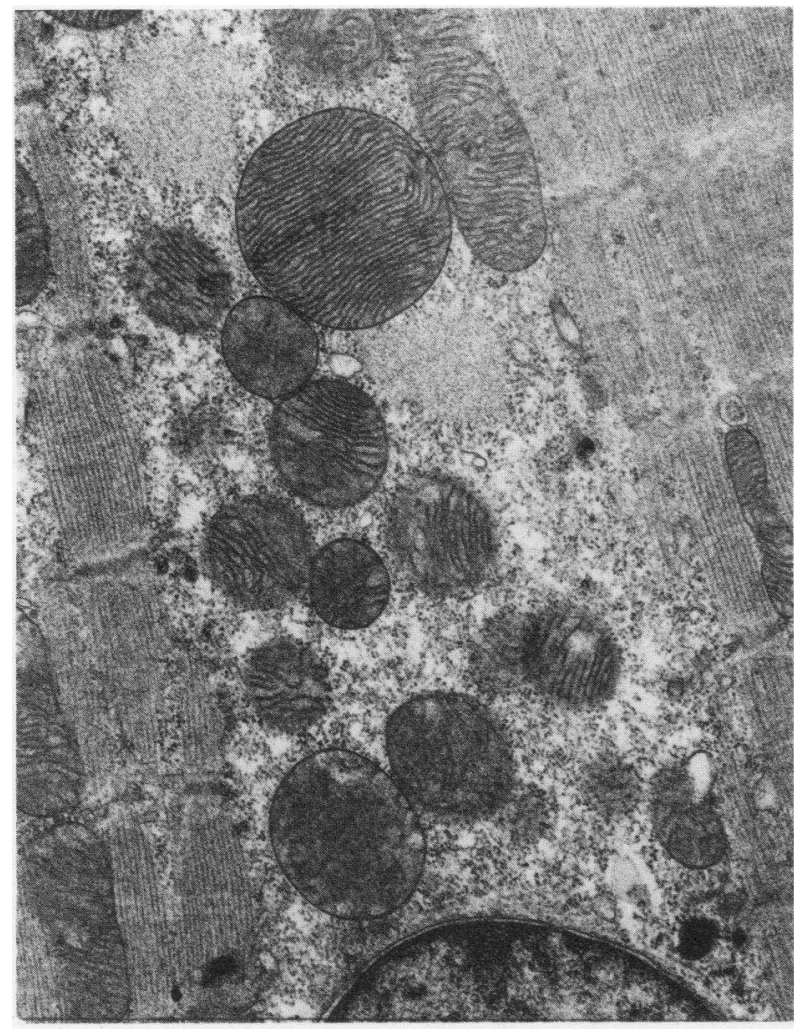

FIGURE 8 An electron micrograph of a normal euthyroid control. $\times 16,000$.

served on electron microscopy. An additional consideration is that hypothyroidism may interfere with the inflammatory process that may have a role in the containment of necrosis (48). In this study, the severity of reduced thyroid hormone may have masked a potentially beneficial influence that might have been present with less severe interruption of normal metabolism.

The absence of a reduction in first derivative of left ventricular pressure $(d P / d t)$ rise, plausibly viewed as one index of contractility is, on first appearance, inconsistent with in vitro studies which have shown a reduction in contractile function of hypothyroid papillary muscle (49), or studies in lightly anesthetized hypothyroid dogs which have shown a displacement of the tension-velocity relationship of the left ventricle (50). In vitro studies are devoid of neural and humoral regulation, and we suspect that the absence of reduced contractility in this conscious canine model may be due to supportive neural and humoral reflexes known to be initiated by reduction in mean systemic pressure. The study of conscious animals without the neural inhibition caused by anesthesia or surgical manipulation may yield different results than preparations devoid of humoral and neural regulation (51). In this regard, the severe reduction of thyroid function and resulting re-

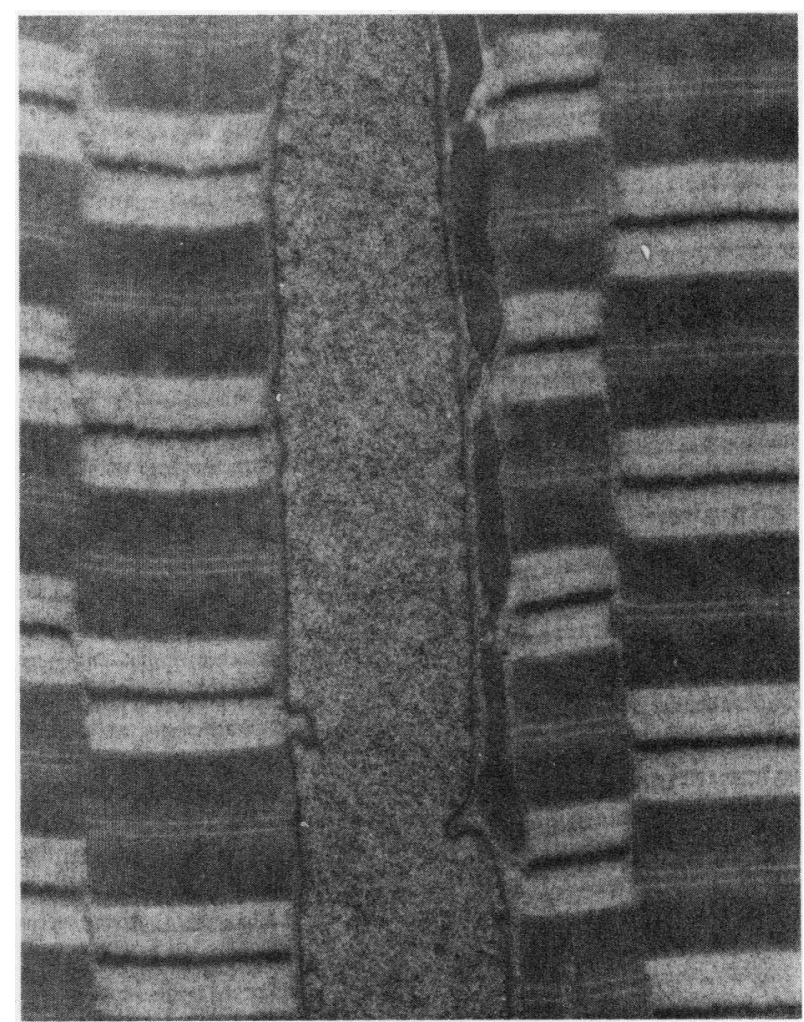

FIGURE 9 An electron micrograph from a hypothyroid dog demonstrating reduced number of mitochondria with large areas of tissue totally devoid of mitochondria. $\times 14,000$.

flexes may account for the absence of bradycardia in these dogs.

Hypothyroidism resulted in a detrimental influence on ischemic dysrhythmias even when infarct size between the hypothyroid and euthyroid dogs were similar. It was necessary to match infarct size obtained from two control groups to properly account for the effect of infarct size on the severity of dysrhythmias (23). This detrimental influence of hypothyroidism is consistent with increasing evidence that ischemic dysrhythmias are associated with significant metabolic abnormalities (52). The precise mechanism of this hypometabolic detrimental influence on ischemic dysrhythmias remains unexplained, but apparently it is not related to the extent of infarction.

We measured the extent of infarction by determining CK depletion measured directly from the heart. In a previous study we demonstrated that the enzyme activity of CK is not dependent on thyroxine, and that the altered plasma levels of CK present in altered states of thyroid function in dogs were the results of alterations of the peripheral disappearance of the enzyme (22). However in patients, severe myxedema may cause gross cardiac pathology and elevated plasma CK, presumably as a result of intracellular release of both 


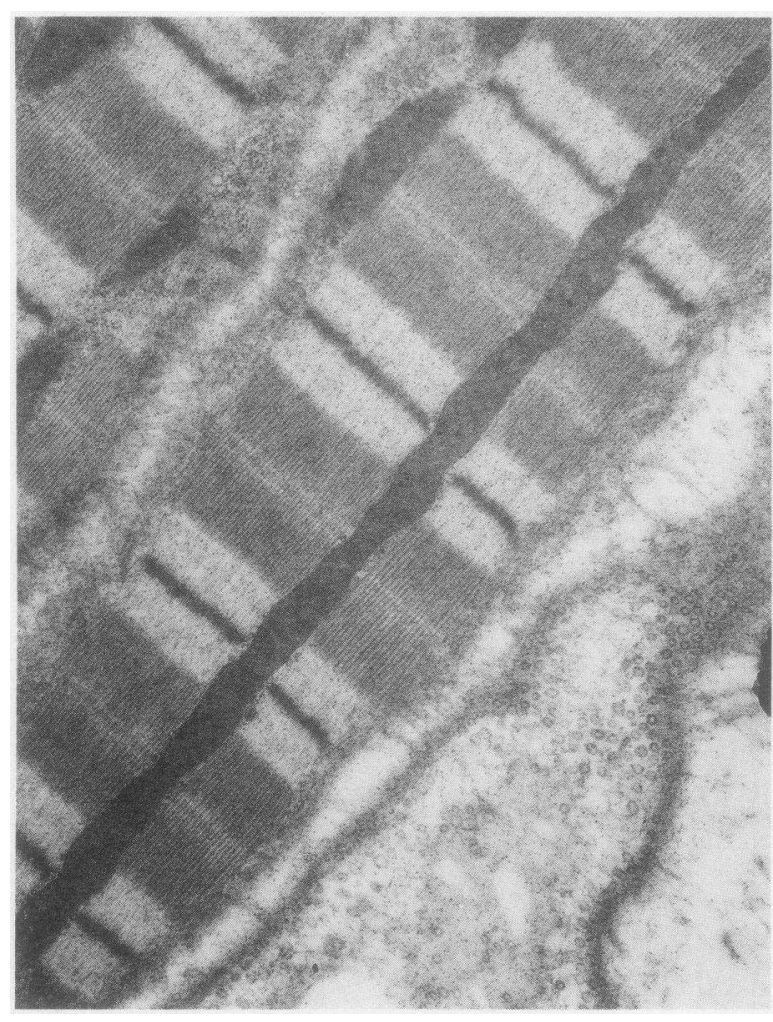

Figure 10 An electron micrograph from a hypothyroid dog demonstrating unusual elongated, rod shaped mitochondria. $\times 16,000$.

myocardial and skeletal CK $(53,54)$. There was no evidence of gross cardiac pathology or myocardial CK depletion caused by myxedema in this study. The deleterious influence of hypothyroidism on the extent of ischemic damage is supported by multiple factors; nevertheless, further studies using additional measures of infarct size, in addition to CK depletion, may be helpful.

Electron microscopic studies suggest that the preocclusion microarchitecture was abnormal. The appearance of reduced number of mitochondria are consistent with the reduced myocardial oxygen consumption present in hypothyroid tissue. Using quantitative mathematical techniques on hypothyroid rat myocardium, others have reported that the membrane area of mitochondrial cristae per unit of myofibrillar volume is reduced in the hypothyroid state and increased in the hyperthyroid state (55). With thyroxine treatment, the volume of mitochondria increases and additional mitochondria may be present (55). However, further studies with quantitative morphometric approaches are indicated to confirm the findings of a reduced number of myocardial mitochondria in severely hypothyroid dog myocardium as our findings are qualitative.

Elongated mitochondria such as present in this study have previously been reported in several animal studies of various types of cardiomyopathy (56), but have not been reported in the very limited electron micrographic studies of human hypothyroid hearts (57). The exact causes of these elongated mitochondria have not been elucidated, although fusion of several mitochondria has been suggested as one possible mechanism (58). Furthermore, it is not known whether these changes may have lead to a heightened sensitivity to ischemia and, therefore, to a larger infarct size in hypothyroid dogs, or if these elongated mitochondria are related to the severity of hypothyroidism present in this study.

Finally, although hypometabolic interventions may be of potential benefit to evolving myocardial infarction, the results of this study show that one form of hypometabolism, hypothyroidism, resulted in an overall detrimental effect when studied in conscious dogs. We do not suggest from these studies that hypometabolism per se is detrimental to ischemic myocardium since hypothyroidism in this model with intact autoregulation did not result in a pure metabolic intervention. However, the direct and indirect effects of hypothyroidism, including hypometabolism, changes in microarchitecture and hemodynamics, and enhancement of ischemic dysrhythmias, were associated with a detrimental effect of evolving infarction in this conscious animal model. We cannot exclude the possibility that a beneficial metabolic effect was overwhelmed by hemodynamic or other alterations. The precise roles for each of these factors in causing the extension of necrosis has not been defined. This model resembles the clinical situation where interventions directed at a single physiologic endpoint may affect multiple factors (59). Accordingly, caution should be taken when applying hypometabolic interventions to ischemic myocardium as the beneficial manipulation of one variable that affects ischemic myocardium may lead to an overall deleterious effect by the inadvertent manipulation of the multiple factors that influence ischemic myocardium.

\section{ACKNOWLEDGMENTS}

The authors acknowledge the assistance of Barbara Brandt and Renee Besta, and Dr. James B. Caulfield, University of South Carolina, for assistance in interpretation of electron micrographs, and Natalie Pakiz for secretarial assistance.

This work was supported by American Heart Association California Affiliate grant-in-aid 79-S155, 80-S127 and Veterans Administration Institutional Support.

\section{REFERENCES}

1. Blumgart, H. L., S. A. Levine, and D. D. Berlin. 1933. Congestive heart failure and angina pectoris. The therapeutic effect of thyroidectomy in patients without clinical or pathological evidence of thyroid toxicity. Arch. Intern. Med. 51: 866-877. 
2. White, P. D. 1960. The choice of therapy in the management of refractory angina pectoris. Prog. Cardiovasc. Dis. 3: $97-107$.

3. Corday, E., H. L. Jaffe, and D. W. Irving. 1960. Hypometabolic treatment of heart disease. Am. J. Cardiol. 6: 952-960.

4. Preston, T. A. 1977. The placebo effect. In Coronary Artery Surgery: A Critical Review (by T. A. Preston). Raven Press, New York. 6: 81-99.

5. Sobel, B. E. 1974. Salient biochemical features in ischemic myocardium. Circ. Res. 34-35(Suppl. 111): 173-181.

6. Rasmussen, M. M., K. A. Reimer, R. A. Kloner, and R. B. Jennings. 1977. Infarct size reduction by propranolol before and after coronary ligation in dogs. Circulation. 56: 794-798.

7. Shell, W. E., and B. E. Sobel. 1974. Protection of jeopardized ischemic myocardium by reduction of ventricular afterload. N. Engl. J. Med. 291: 481-486.

8. Maroko, P. R., P. Libby, W. R. Ginks, C. M. Bloor, W. E. Shell, B. E. Sobel, and J. R. Ross. 1972. Coronary artery reperfusion. I. Early effects on local myocardial function and the extent of myocardial necrosis. J. Clin. Invest. 51: 2710-2716.

9. Sterling, K., P. O. Milch, M. A. Brenner, and J. H. Lazarus. 1977. Thyroid hormone action: The mitochondrial pathway. Science (Wash. D. C.). 197: 996-999.

10. Rasmussen, H. 1941. Influence of thyroid hormone on heart and circulation; experimental investigation in dogs. Acta Med. Scand. 115(Suppl.): 1-202.

11. Sodi-Pallares, D., J. Ponce De Leon, A. Bisteni, and G. A. Medrano. 1969. Potassium, glucose and insulin in myocardial infarction. Lancet. I: 1315-1316.

12. Opie, L. H., K. Bruyneel, and P. Owen. 1975. Effects of glucose, insulin and potassium infusion on tissue metabolic changes within first hour of myocardial infarction in the baboon. Circulation. 52: 49-57.

13. Smithcors, J. F. 1964. The endocrine system. In Anatomy of the Dog. Malcom E. Miller, editor. W. R. Saunders Co., Philadelphia, Pa. 16: 807-829.

14. Kallfelz, F. A., and R. P. Erali. 1973. Thyroid function tests in domesticated animals: free thyroxine index. Am.J. Vet. Res. 34: 1449-1451.

15. Rudolph, A. M., and M. A. Heymann. 1967. Circulation of the fetus in utero. Methods for studying distribution of blood flow, cardiac output and organ blood flow. Circ. Res. 21: 163-184.

16. Domenech, R. J., J. I. E. Hoffman, M. I. M. Noble, K. B. Saunders, J. R. Henson, and S. Subijanto. 1969. Total and regional coronary blood flow measured by radioactive microspheres in conscious and anesthetized dogs. Circ. Res. 25: 581-596.

17. Karlsberg, R. P., P. D. Henry, S. A. Ahmed, B. E. Sobel, and R. Roberts. 1977. Lack of protection of ischemic myocardium by verapamil in conscious dogs. Eur. J. Pharmacol. 42: 339-346.

18. Karlsberg, R. P., P. A. Kenkoske, P. E. Cryer, R. B. Corr, and R. Roberts. 1979. Rapid activation of the sympathetic nervous system following coronary artery occlusion: relationship to infarct size, site, and haemodynamic impact. Cardiovasc. Res. 13: 523-531.

19. Kjekshus, J. K., and B. E. Sobel. 1970. Depressed myocardial creatine phosphokinase activity following experimental myocardial infarction in rabbit. Circ. Res. 27: 403-414.

20. Weiss, E. S., S. A. Ahmed, M. J. Welch, J. R. Williamson, M. M. Ter-Pogossian, and B. E. Sobel. 1977. Quantification of infarction in cross sections of canine myocardium in vivo with positron emission transaxial tomography and ${ }^{11} \mathrm{C}$-palmitate. Circulation. 55: 66-73.

21. Karlsberg, R. P., B. E. Sobel, and R. Roberts. 1976. A standardized model for assessment of early interventions designed to protect ischemic myocardium. Physiologist. 19: 249. (Abstr.)

22. Karlsberg, R. P., and R. Roberts. 1978. Effect of altered thyroid function on plasma creatine kinase clearance in the dog. Am. J. Physiol. 235: E614-E618.

23. Roberts, R., A. Husain, D. Ambos, G. C. Oliver, J. R. Cox, and B. E. Sobel. 1975. Relation between infarct size and ventricular arrhythmia. Br. Heart J. 37: 1169-1175.

24. Williams, T. H., and J. Y. Jew. 1975. An improved method for perfusion fixation of neural tissues for electron microscopy. Tissue Cell. 7: 407-418.

25. Wallace, A. G., N. S. Skinner Jr., and J. R. Mitchell. 1963. Hemodynamic determinants of the maximal rate of rise of left ventricular pressure. Am. J. Physiol. 205: 30-36.

26. Goh, K., and R. D. Dallam. 1957. Oxygen consumption of the auricles, right and left ventricles of the normal, hypothyroid and hyperthyroid rat heart. Am. J. Physiol. 188: 514-518.

27. Cross, C. E., P. A. Rieben, and P. F. Salisbury. 1961. Coronary driving pressure and vasomotor tonus as determinants of coronary blood flow. Circ. Res. 9: 589-600.

28. Eckenhoff, J. E., C. M. Hafkenschiel, C. M. Landmesser, and M. Harmel. 1947. Cardiac oxygen metabolism and control of coronary circulation. Am. J. Physiol. 149: 634-649.

29. Scott, J. B., R. A. Hardin, and F. J. Haddy. 1960. Pressureflow relationships in the coronary vascular bed of the dog. Am. J. Physiol. 199: 765-769.

30. Maroko, P. R., J. K. Kjekshus, B. E. Sobel, T. Watanabe, J. W. Covell, J. Ross Jr., and E. Braunwald. 1971. Factors influencing infarct size following coronary artery occlusion. Circulation. 43: 67-82.

31. Graham, T. P. Jr., J. W. Covell, E. H. Sonnenblick, J. Ross Jr., and E. Braunwald. 1968. Control of myocardial oxygen consumption: relative importance of contractile state and tension development. J. Clin. Invest. 47: 375-385.

32. Sonnenblick, E. H., J. Ross Jr., and E. Braunwald. 1968. Oxygen consumption of the heart: Newer concepts of its multifocatorial determinations. Am. J. Cardiol. 22: 328-336.

33. Zaimis, E., L. Papadaki, A. S. F. Ash, E. Larbi, S. Kakari, M. Matthew, and A. Paradelis. 1969. Cardiovascular effects of thyroxine. Cardiovasc. Res. 3: 118-133.

34. Skelton, C. L., F. E. Karch, and K. Wildenthal. 1973. Lack of acute effects of thyroid hormones on myocardial contractility. Am. J. Physiol. 224: 957-962.

35. Braunwald, E. 1971. Control of myocardial oxygen consumption: Physiologic and clinical considerations. Am. J. Cardiol. 27: 416-432.

36. Sanford, C. F., E. E. Griffin, and K. Wildenthal. 1978. Synthesis and degradation of myocardial protein during the development and regression of thyroxine-induced cardiac hypertrophy in rats. Circ. Res. 43: 688-694.

37. Levey, G. S. 1971. Catecholamine sensitivity, thyroid hormone and the heart: A reevaluation. Am. J. Med. 50: 413-420.

38. Tedesco, J. L., K. V. Flattery, and E. A. Sellers. 1977. Effects of thyroid hormones and cold exposure on turnover of norepinephrine in cardiac and skeletal muscle. Can. J. Physiol. Pharmacol. 55: 515-522.

39. Wollenberger, A., and L. Will-Shahab. 1976. Influence of thyroid state on the specific binding of noradrenaline to a cardiac particulate fraction and on catecholamine- 
sensitive cardiac adenylate cyclase activity. Sarcolemma. 9: 193-203.

40. Williams, R. S., and R. J. Lefkowitz. 1979. Thyroid hormone regulation of alpha-adrenergic receptors: studies in rat myocardial. J. Cardiovasc. Pharmacol. 1: 181-189.

41. Levey, G. S., C. L. Skelton, and S. E. Epstein. 1969. Decreased myocardial adenyl cyclase activity in hypothyroidism. J. Clin. Invest. 48: 2244-2250.

42. Broekhuysen, J., and M. Ghislain. 1972. Increased heart adenycyclase activity in the hypothyroid rat. J. Biochem. Pharmacol. 21: 1493-1500.

43. Philipson, K. D., and I. S. Edelman. 1977. Thyroid hormone control of $\mathrm{Na}+-\mathrm{K}+-\mathrm{ATP}$ ase and $\mathrm{K}+$-dependent phosphatase in rat heart. Am.J. Physiol. 232: C196-C201.

44. Suko, J. 1973. The calcium pump of cardiac sarcoplasmic reticulum. Functional alterations at different levels of thyroid state in rabbits. J. Physiol. (Lond.). 228: 563-582.

45. Morkin, E. 1979. Stimulation of cardiac myosin adenosine triphosphatase in thyrotoxicosis. Circ. Res. 44: 1-7.

46. Wollenberger, A., E. G. Krause, and L. Macho. 1964. Thyroid state and the activity of glycogen phosphorylase in ischemic myocardium. Nature (Lond.). 201: 789-791.

47. Sterling, K. 1979. Thyroid hormone action at the cell level. N. Engl. J . Med. 300: 117-123.

48. Krantz, D., A. Hecht, and I. Furhmann. 1976. The influence of hyperthyroidism and hypothyroidism on the wound healing of experimental myocardial infarction in the rat. Exp. Pathol. (Jena). 12: 129-136.

49. Buccino, R. A., J. F. Spann Jr., P. E. Pool, E. H. Sonnenblick, and E. Braunwald. 1967. Influence of the thyroid state on the intrinsic contractile properties and energy stores of the myocardium. J. Clin. Invest. 46: 1669-1682.

50. Taylor, R. R., J. W. Covell, and J. Ross, Jr. 1969. Influence of the thyroid state on left ventricular tension-velocity relations in the intact, sedated dog. J. Clin. Invest. 48: 775-784.

51. Vatner, S. F., and E. Braunwald. 1975. Cardiovascular control mechanisms in the conscious state. N. Engl. J. Med. 293: 970-976.

52. Opie, L. H. 1975. Metabolism of free fatty acids, glucose and catecholamines in acute myocardial infarction. Relation to myocardial ischemia and infarct size. Am. J. Cardiol. 36: 938-953.

53. Doran, G. R., and J. H. Wilkinson. 1975. The origin of the elevated activities of creatine kinase and other enzymes in the sera of patients with myxoedema. Clin. Chim. Acta. 62: 203-211.

54. Nagamine, M., and I. Furukawa. 1972. Increased activities of serum enzymes predominating in heart muscle in patients with hypothyroidism. Report of two cases.Jpn. Circ. J. 36: 47-53.

55. Page, E., and L. P. McCallister. 1973. Quantitative electron microscopic description of heart muscle cells. Am.J. Cardiol. 31: 172-181.

56. Caulfield, J. B. 1963. Fine structure of normal and diseased heart. Prog. Cardiovasc. Dis. 5: 610-630.

57. Ferrans, V. J., R. A. Massumi, G. I. Shugoll, A. Nayab, and W. C. Roberts. 1973. Ultrasound studies of myocardial biopsies in 45 patients with obstructive or congestive cardiomyopathy. In Recent advances in studies on cardial structure and metabolism. E. Bajusz, and G. Rona, editors. University Park Press, Baltimore, Md. 2: 231-271.

58. Wollenberger, A., and W. Schulze. 1961. Mitochondrial alterations in the myocardium of dogs with aortic stenosis. J. Biophys. Biochem. Cytol. 10: 285-288.

59. Karlsberg, R. P., and W. S. Aronow. 1980. Reduction of myocardial infarct size: Approach for the 80's. Arch. Intern. Med. 140: 616-619. 